Marquette University
e-Publications@Marquette

Electrical and Computer Engineering Faculty Research and Publications

Electrical and Computer Engineering,

\title{
$9-2014$
}

\section{Generalized Approach of Stator Shifting in Interior Permanent- Magnet Machines Equipped with Fractional-Slot Concentrated Windings}

\author{
Patel B. Reddy \\ General Electric \\ Kum-kang Huh \\ General Electric \\ Ayman M. EL-Refaie \\ Marquette University, ayman.el-refaie@marquette.edu
}

Follow this and additional works at: https://epublications.marquette.edu/electric_fac

Part of the Computer Engineering Commons, and the Electrical and Computer Engineering Commons

\section{Recommended Citation}

Reddy, Patel B.; Huh, Kum-kang; and EL-Refaie, Ayman M., "Generalized Approach of Stator Shifting in Interior Permanent-Magnet Machines Equipped with Fractional-Slot Concentrated Windings" (2014). Electrical and Computer Engineering Faculty Research and Publications. 665.

https://epublications.marquette.edu/electric_fac/665 
Marquette University

e-Publications@Marquette

\section{Electrical and Computer Engineering Faculty Research and Publications/College of Engineering}

This paper is NOT THE PUBLISHED VERSION.

Access the published version via the link in the citation below.

IEEE Transactions on Industrial Electronics, Vol. 61, No. 9 (September 2014): 5035-5046. DOI. This article is (C) The Institute of Electrical and Electronics Engineers and permission has been granted for this version to appear in e-Publications@Marquette. The Institute of Electrical and Electronics Engineers does not grant permission for this article to be further copied/distributed or hosted elsewhere without the express permission from The Institute of Electrical and Electronics Engineers.

\section{Generalized Approach of Stator Shifting in Interior Permanent-Magnet Machines Equipped with Fractional-Slot Concentrated Windings}

Patel B. Reddy

GE Global Research Center, Niskayuna, NY

Kum-Kang Huh

GE Global Research Center, Niskayuna, NY

Ayman M. EL-Refaie

GE Global Research Center, Niskayuna, NY 


\section{Abstract:}

Electrical drive systems, which include electrical machines and power electronics, are a key enabling technology for advanced vehicle propulsion systems that reduce the petroleum dependence of the ground transportation sector. To have significant effect, electric drive technologies must be economical in terms of cost, weight, and size while meeting performance and reliability expectations. Interior permanent magnet machines with fractional-slot concentrated windings have been shown to be good candidates for hybrid traction applications. One of the key challenges is the additional stator magnetomotive force sub- and superharmonic components that lead to higher losses in the rotor as well as saturation effects. This paper tries to address this issue by looking into the concept of stator shifting. The generalized concept of stator shifting in the context of the harmonic components that are targeted for cancellation is presented; the focus is on single-layer and doublelayer windings that have stator space subharmonics. It is shown that the stator shifting can reduce the lossproducing harmonics on the rotor as well as help the flux weakening performance of the fractional-slot concentrated winding designs. The cancellation of the loss harmonics is introduced as a method in which a particular harmonic can be targeted as well as reduce the phase inductance of the machine allowing for more room in terms of the operating voltage at higher speed. The concept of stator shifting will be explained, and the effect of varying the shift angle on the various harmonic components and winding factors will be investigated. Various designs, arising out of single-layer and double winding layer 10-pole, 12-slot configuration (targeting the FreedomCAR specifications) with varied shift angles are evaluated. The comparison between these designs in terms of their power density, efficiency, and torque ripple is presented.

Nomenclature

\begin{tabular}{|c|l|}
\hline$n:$ & Stator magnetomotive force (MMF) harmonic order. \\
\hline$p:$ & Number of poles in the machine. \\
\hline$\alpha:$ & Electrical shift angle for the working harmonic. \\
\hline$k_{\text {wn-final }}:$ & Winding factor of the nth harmonic component after stator shifting. \\
\hline$k_{\text {wn-initial }}:$ & Winding factor of the nth harmonic component before stator shifting. \\
\hline
\end{tabular}

\section{SECTION I. Introduction}

INTERIOR permanent-magnet (IPM) machines equipped with fractional-slot concentrated windings (FSCW) are good candidates for high-speed traction applications. This is mainly due to the higher power density and efficiency that can be achieved [1]. The main challenge with this type of machines is the high rotor losses at high speeds/frequencies as well as saturation effects due to the high content of sub- and superstator MMF components.

In FSCW IPM machines, the torque-producing harmonic is a higher order harmonic, which can be different than the first (or fundamental) harmonic component derived from the winding function. The fundamental harmonic component in most cases determines the subharmonic losses [2], which represent the majority of the highspeed losses particularly on the rotor side. Usually, there is a tradeoff involved in the selection of the optimum slot/pole combinations. In the configurations, where the winding factor of the torque-producing harmonic component is quite high, the power density is maximized. However, if the winding factor of the fundamental or the first loss-producing harmonic component is high, the configuration also yields high subharmonic losses or, in other words, has low efficiency.

There have been several attempts in literature to investigate ways to mitigating the effect of these additional harmonics. The difference between single- and double-layer FSCW in the case of surface PM (SPM) machines has been extensively investigated in literature [3]-[4][5]. Recently, there has been growing interest in higher 
number of winding layers (e.g., three and four layers) [6]-[7][8]. The goal was by going to higher number of layers, the most-dominant loss-producing harmonic components can be reduced.

Nakano [7] looks at the sub- and superharmonics identifying the suitable designs based on "rate of eddy current loss," which by itself is based on the MMF of the other harmonics. Although an explicit relation of the eddy current loss with harmonics is absent, various designs belonging to slot/pole/phase combinations of $1,1 / 2,3 / 5$, $3 / 4$, and $4 / 5$ are compared on this relative scale, with the final emphasis on 1 slot/pole/phase combination.

Studies by Di Gerlando [11] regarding the study of multilayer windings in the application of electric traction have not been very conclusive. Kometani et al. [9] considered the cases with the slot number being multiple of 9, i.e., number of slots being $9 \mathrm{n}$, where $\mathrm{n}$ is an integer, and the rotor having eight poles, effectively making a configuration of $3 / 8$ slot/pole/phase. He concluded that the issue of radial forces can be solved by making the slot number as a multiple of 18 , where the radial forces are cancelled by symmetry.

Still the focus is mainly on SPM machines. In the case of SPM machines, there is usually a clear tradeoff involved in introducing of multiple winding layers. On one hand, higher number of layers is known to reduce the harmonic content in the winding function, making it more sinusoidal and hence reducing the additional harmonic losses. On the other hand, the winding factor of the torque-producing harmonic component is also reduced, leading to reduction in machine torque density. In case of FSCW IPM machines the tradeoff is more interesting due to the presence of saliency. In this case, the reduction of loss-producing harmonics will have an effect on both the machine efficiency as well as torque density. This is due to the change in machine saliency (due to saturation effects) and hence reluctance torque contribution.

The concept of harmonic cancellation in fractional slot concentrated winding permanent magnet machines has been further investigated in Dajaku [12] and Reddy [13]. Dajaku [12] presented a shifted stator technique showing better efficiencies at lower speeds, while losing efficiency and performance at higher speeds. The paper showed one specific example and again was focusing on SPM machines. Reddy [13] used the concept of multiple layer windings to reduce the harmonic content in the machines, i.e., going from double layer to four layer windings. However, it is seen that such a technique mainly reduces the fundamental subharmonic, while it has minimal impact on higher order harmonics reducing the potential improvement in efficiency.

The general concept of harmonic cancellation by stator shifting is a relatively known topic [16]. One variation of this concept is short pitching which is typically used in distributed winding configurations to eliminate harmonics.

The goal of this paper is to investigate the concept of stator shifting in the case of FSCW IPM machines in a more general and systematic way for different number of layers as well as different slot/pole combinations in order to establish the performance tradeoff trends.

For all the designs analyzed in the paper, emphasis in terms of performance will be placed on the machine power density, efficiency, flux weakening performance, and torque ripple. The concept of stator shifting will be applied to the designs belonging to two different slot/pole configuration as well as different number of layers. The designs analyzed are based on the DoE FreedomCar specifications [14] summarized in Table I.

TABLE I Summary of Key Freedom Car Advanced Traction Motor Performance Requirements

\begin{tabular}{|l|l|}
\hline Parameter/Metric & Value \\
\hline Peak Power @ 2800 r/min & $55 \mathrm{~kW}$ \\
\hline Maximum Speed & $14,000 \mathrm{r} / \mathrm{min}$ \\
\hline Continuous Power & $30 \mathrm{~kW}$ \\
\hline Mass Power Density for total machine & $>1.6 \mathrm{~kW} / \mathrm{kg}$ \\
\hline Vol. Power Density for total machine & $>5.67 \mathrm{~kW} / \mathrm{I}$ \\
\hline
\end{tabular}




\begin{tabular}{|l|l|}
\hline Constant Power Speed Ratio & $5: 1$ \\
\hline Maximum Phase Current & $400 \mathrm{Arms}$ \\
\hline Peak Line-to-Line back-emf@2800 r/min & $600 \mathrm{~V}$ \\
\hline Efficiency at 20\% Rated Torque up to the max. speed & $>95 \%$ \\
\hline
\end{tabular}

\section{SECTION II. Concept of Stator Shifting}

The concept of "stator shifting" is to use two FSCW stators belonging to the same slot/pole combination to form a "combined" machine having lower harmonics, while maintaining the torque producing capability. The two stators are shifted by an electrical angle, which we will denote in this paper as the "shift" angle " $\alpha$," and combined to form the final machine, while the rotor is not changed. During the combination of the two stators, the slots of one stator will be inserted between the slots of the other stator and winding overlaps will occur. The two individual winding configurations presented in the final machine are placed in series with each other, so as to produce the maximum benefit of the final machine as well as to eliminate the possibility of circulating currents. Thus, the final machine has double the number of slots (hence double the number of coils) of each individual machine, while more importantly having the same number of poles as each individual machine (hence the same electrical frequency). Furthermore, all changes are done on the stator side of the motor and rotor does not need to change in this technique.

The notation of the shift angle is indicative of the mechanical shift of the two stators. The shift angle " $\alpha$ " is defined as the electrical angle of the second shifted stator with respect to the first stator. In other words, the angle $\alpha$ is the electrical shift of the working (torque-producing) harmonic of the second stator with respect to the working (torque-producing) harmonic of the first stator. Since the working harmonic of these FSCW machines is not the fundamental, care is to be taken in identifying the correct harmonic while defining the shift angle.

The whole concept of the shift angle is aimed at the reduction of the harmonics in FSCW machines. While the initial design has a tooth winding and is harmonically rich, the final design is expected to have a lower harmonic content and may not necessarily have a tooth winding. In cases, with smaller shift angles, the coil pitch will be similar to the pole pitch and hence can overrun more than two slots, resulting in a pseudo-distributed winding.

Differentiation with the distributed winding is a key benefit in these types of windings. While the coil pitch in the concentrated windings can be unity (tooth windings), the coil pitch in shifted windings is actually two. On the other hand, distributed windings can have coil pitch of at least three (three in a one slot/pole/phase windings), reaching up to six in the widely used two slot/pole/phase windings. In other words, while tooth windings lie at one extreme of the spectrum with extremely short end-windings, and the traditional distributed windings (lap) lie at the other extreme with higher coil pitches. The proposed winding technique has coil pitch of exactly two, making it fall in between and hence has shorter end-windings than distributed windings, while having longer end-windings than tooth windings. The key benefits/tradeoffs involved in implementing this technique are explained in the results of the various slot/pole combinations.

The concept is applied to the 10-pole, 12 -slot configuration (2/5 slot/pole/phase combination) and is shown in Fig. 1. Two stators belonging to the 10-pole, 12-slot configurations are shown. The second stator is shifted by an electrical shift angle $\alpha$, from the first stator. Since the fifth harmonic is the working harmonic in this configuration, the actual stators are shifted by a mechanical angle $\alpha / 5$. The final design shown has both winding configurations. As said before, the rotor is not modified while this transformation is made. 


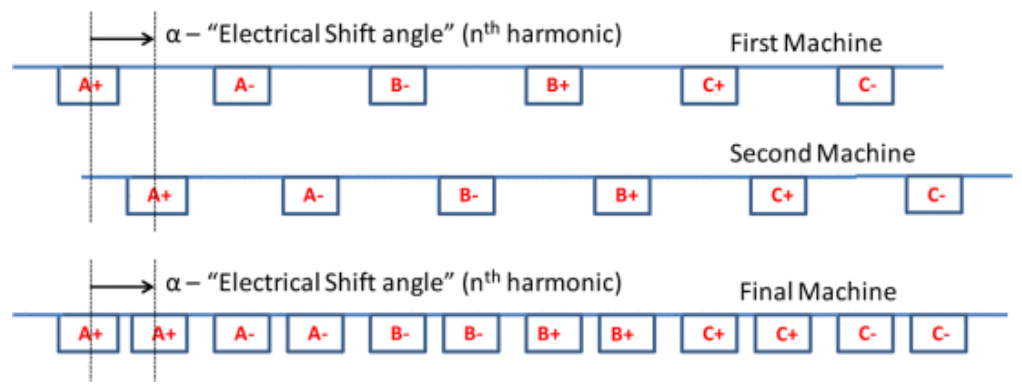

Fig. 1. First and second (shifted from first by the shift angle) and the third (final) machines are shown from top to bottom, respectively (the definition of the shift angle is in electrical degrees of the working harmonic of the first stator).

Figs. 2-4 show the winding configuration for the three "electrical shift angles of $0,360^{\circ}$, and $720^{\circ}$. These shift angles correspond to $0,72^{\circ}$, and $144^{\circ}$ "mechanical" shift angles. It can be seen that these shift angles lead to completely different winding configurations with significantly different harmonic contents as will be discussed later.

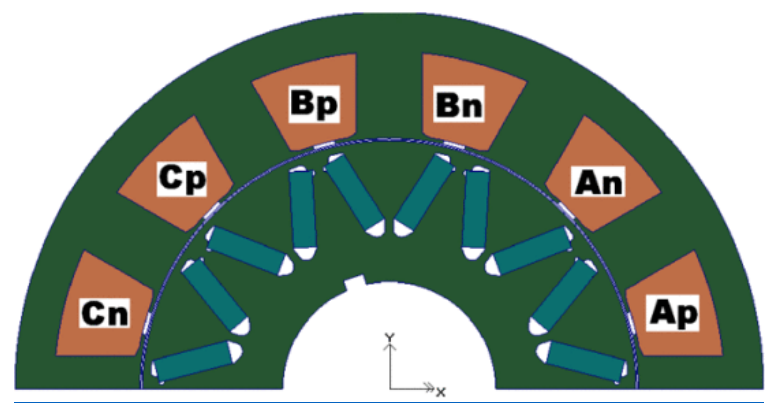

Fig. 2. 10-pole, 12-slot machine with a shift angle of 0.

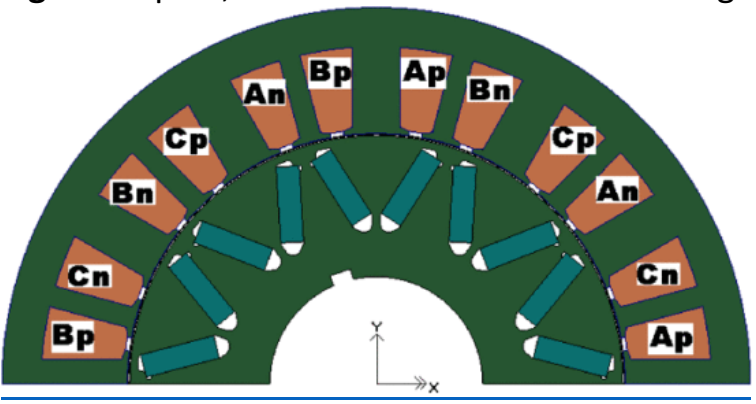

Fig. 3. 10-pole, 12-slot machine with a shift angle of 360.

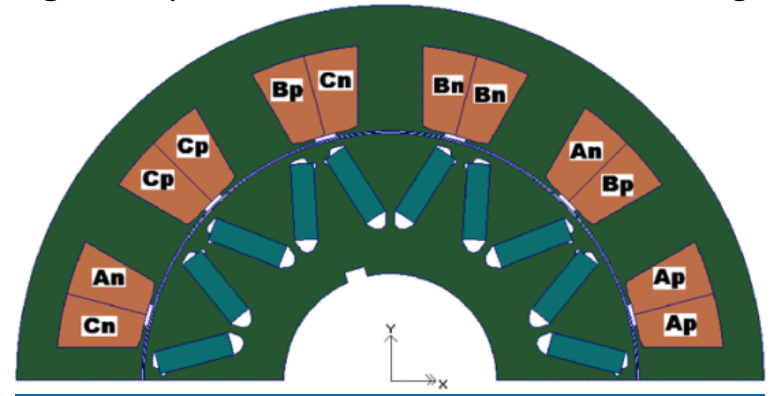

Fig. 4. 10-pole, 12-slot machine with a shift angle of 720. 


\section{SECTION III. Effect of Stator Shiftting on Stator Harmonics and Other Machine Performance Metrics}

The effect of stator shifting on the stator harmonics is explained in the baseline case of 10-pole, 12-slot configuration belonging to the $2 / 5$ slot/pole/phase family with single-layer windings (only one coil side per slot). The harmonic spectrum of a single stator is shown in Fig. 5. Each of the single stators has tooth windings, where the fifth harmonic of the stator interacts with the 10-pole rotor and hence it is the working (torque-producing) harmonic. The presence of the other harmonics including the fundamental (first space harmonic), seventh, 11th, and so, adds to the harmonic losses in the machine.

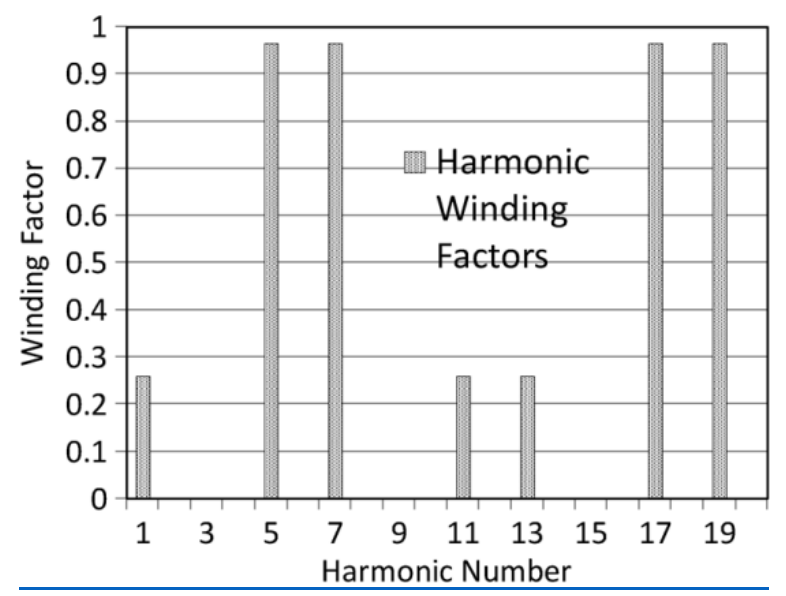

Fig. 5. Harmonic winding factors in $2 / 5$ slot/pole/phase family.

The addition of the second stator can be understood as the addition of shifted harmonic to the similar harmonic of the first stator. In other words, the synchronous harmonic of the first stator adds only to the synchronous harmonic of the second stator, the fifth to fifth, and so on. The final winding factor with the inclusion of the shift is explained using an "attenuation factor" (shift factor/distribution factor), which is a function of the electrical shift angle

$$
k_{\mathrm{wn}-\text { final }}=k_{\mathrm{wn}-\text { initial }} *\left|\cos \left(\frac{n \alpha}{2 p}\right)\right| .
$$

\section{(1)}

The attenuation factor for each harmonic is given in (1), where " $\alpha$ " is the electrical shift angle for the working harmonic, " $n$ " is the harmonic number, and " $p$ " is the number of poles in the machine. The effect of shift angle on the winding factors on the fundamental (first), fifth, and the seventh harmonic of the $2 / 5$ configuration is shown in Fig. 6. 


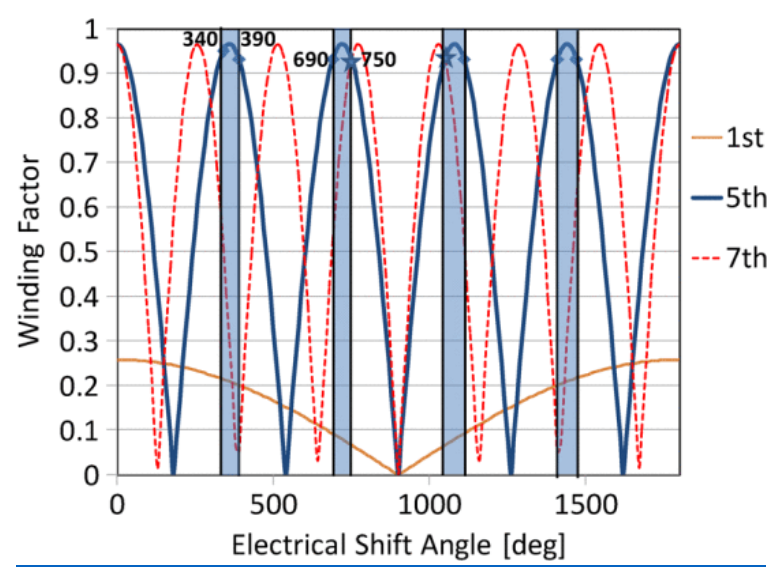

Fig. 6. Effect of the shift angle on winding factors of first, fifth, and seventh harmonics in $2 / 5$ slot/pole/phase family with single-layer windings.

The variation of the attenuation factor is sinusoidal, which means that if proper shift angle is chosen, it is possible to minimize the winding factor for a particular harmonic.

Another explanation of the attenuation factor also means that the variation of winding factor for each harmonic repeats after a specific shift angle corresponding to that harmonic. In other words, multiple shift angles can result in similar values for the winding factor for a particular harmonic.

It is significant to note that the attenuation factor is generic and can be applied to all slot/pole combinations. The factor is only a function of the electrical shift angle and the number of poles.

The attenuation factor (shift factor/distribution factor) is a powerful handle to reduce the harmonic content in the tooth windings, which can lead to reduction in losses and improvement in the machine's power density. As shown in Fig. 6, for the 10-pole configuration, if the chosen shift angle lies in the grey regions, it is possible to get a good winding factor of the working harmonic (fifth), while reducing the two loss-producing harmonics (first and seventh). Stator shift angles of $340^{\circ}$ to $390^{\circ}$, along with $690^{\circ}$ to $750^{\circ}$, are seen to have high winding factors for the torque producing harmonics and are expected to have lower core losses and hence good efficiencies. Additionally a reduction of the higher harmonics is expected to reduce the saturation effects and thereby improving the machine saliency. This dual effect is expected to have a considerable impact on the power density of the final machine.

To understand the effect of shift factor in detail, machine designs considered are based on the 10-pole, 12-slot IPM design considered for high-speed traction application [15]. The specifications presented in Table I have very challenging power density and efficiency targets over the entire speed range up to $14000 \mathrm{r} / \mathrm{min}$.

The principle of stator shifting is applied to this machine, keeping in mind the same number of Amp-turns between the designs in this paper and the design in [15]. This paper will focus on the peak power performances at the corner speed of $2800 \mathrm{r} / \mathrm{min}$ and the continuous power requirement of $30 \mathrm{~kW}$ at $14000 \mathrm{r} / \mathrm{min}$.

In order to provide a meaningful study of the effect of stator shifting, the following design variables were kept constant between the various designs: (a) peak current density of $10 \mathrm{Arms} / \mathrm{mm} 2$, (b) continuous current density of $5 \mathrm{Arms} / \mathrm{mm} 2$, (c) same rotor outer radius, (d) same Amp-turns, and (e) same rotor structure.

Some key metrics in terms of comparing the various designs are power density, saliency ratio, efficiency, torque ripple along with the available power at the top speed, i.e., flux weakening aspect at high speeds. One of the most important metrics is the peak power density, which is defined as the ratio of the peak power of $55 \mathrm{~kW}$ to the minimum mass possible. In other words, with constant amp-turns in the machine and air-gap radius and 
keeping in mind the saturation characteristics of the material mainly in terms of the yoke thickness, each of the designs is semi-optimized to provide the minimum stack length, while providing the peak power of $55 \mathrm{~kW}$.

One of the other key metrics is the efficiency of the machine while providing a power of $30 \mathrm{~kW}$ at the top of speed $14000 \mathrm{r} / \mathrm{min}$ (the top speed is decided by the mechanical integrity of the rotor and the rotor has been already mentioned to be kept the same between different designs). The estimation of the copper losses is based on the MLT of the overlapping windings while the core losses and the magnet losses are based on transient finite element analysis (FEA) with motion. The software used is Magnet (software by Infolytica). The core loss calculations are based on Fourier analysis of the flux densities on an element-by-element basis over the entire core section. The core loss equation is based on the Steinmetz equation incorporating both the hysteresis and eddy current losses based on the loss characteristics of the core lamination material used. The time window for averaging the loss calculation for the stator is given as one electric cycle, while the time window for the rotor is given as the cycle for the sixth harmonic produced from the stator side. The software provides the freedom of assigning the core-loss coefficients for the core losses which we assigned based on test results on the lamination materials used. Also, the core loss calculations in case of the 12 slot/10 pole design were verified by the experimental results included in the appendix of [1].

The other two metrics which are also used to compare the designs are saliency ratio and torque ripple. Saliency ratio has been defined as the ratio of the q-axis inductance to the $d$-axis inductance. The inductance calculations have been based on the peak power operating point at $2800 \mathrm{r} / \mathrm{min}$, which also includes the nonlinear characteristics of the core material.

The mesh used in the FEA is shown in Fig. 7. There are four layers of elements in the air gap. The number of cycles run for each analysis is slightly higher than unity, with care taken to eliminate the initial transient. Effectively the number of steps in one cycle is 120 , with the total number of steps being 130 , to accommodate the above statement.

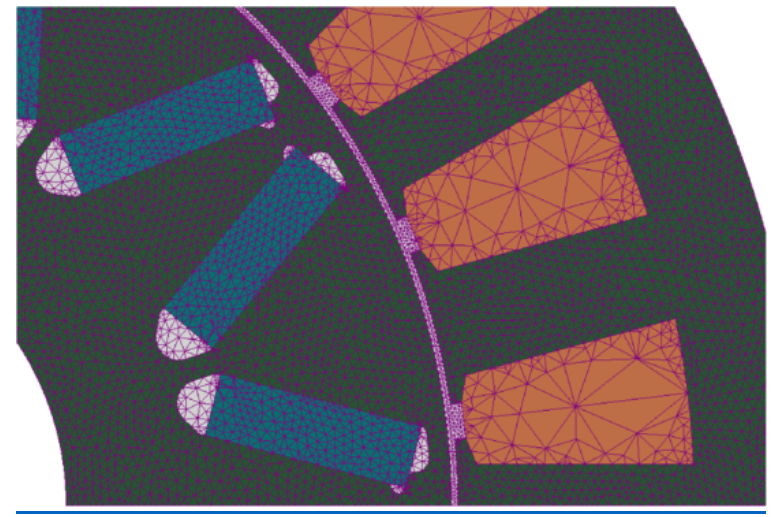

Fig. 7. Meshing for 10 -pole, 24 slot $2 / 5$ double-layer design.

Stator shifting has different effects on different types of FSCW. FSCW are divided mainly into 1) single-layer windings and 2) double-layer windings. For the same slot/pole/phase (spp), the key difference between the single- and double-layer windings is in the magnitude of the stator subharmonic MMF component. This is one of the key loss-producing harmonic components in FSCW machines. Since the stator shifting technique is able to target a specific harmonic while affecting the other harmonics, it is expected that the identification of optimal angle leads to different results in single and double-layer windings. In some cases, we might get better results by targeting the subharmonic component, and, in other cases, we might get better performance by targeting the superharmonic components. Hence, the effect in single and double-layer windings is studied taking the $2 / 5 \mathrm{spp}$ family into consideration. The $2 / 5 \mathrm{spp}$ family is special because it can support both single and double-layer 
winding configurations. Accordingly, the following Sections IV and V will explore the effect of stator shifting on both single- and double-layer winding configurations, respectively. A summary of corresponding results for other spp families will be included in the appendix.

The concept of stator shifting can also be generalized as the combination of two stators with " $n$ " slots forming a final stator with " $2 n$ " slots. The concept begins first with the identification of working harmonic. In a stator containing " $n$ " slots, with " $p$ " number of pole-pairs, the working harmonic is usually, " $p$ " (note that $p$ may not be 1 , i.e., the fundamental harmonic may not necessarily produce torque). The stator shift angle is noted as the electrical angle by which the second stator would be shifted relative to the first stator. The units of the stator shift angle are in the electrical degrees of the " $p$ " harmonic. In other words, if the electrical shift of the second stator is " $\theta$ " degrees, the mechanical shift of the second stator is $\theta / p$ degrees. If the electrical shift angle $\theta$ lies around $180^{\circ}$, it is obvious that the two working harmonics from either of the stators are equal and opposite and would cancel each other. The only two operable ranges for the final stator are the shift angles around $360^{\circ}$ and $720^{\circ}$. In the first, the superharmonic, i.e., the $p+2$ harmonic is reduced while in the second range, the fundamental harmonic is reduced. In other words, the first range affects the super harmonics in the machine while the second range affects the fundamental harmonic. Accordingly, the winding factors and the losses in the machine are affected. Both of the ranges also affect the inductance in the machine, due to which the flux weakening is affected in the machine.

\section{SECTION IV. Effects of Stator Shifting on Single-Layer Windings}

As previously mentioned, this section deals with single-layer FSCW configurations with a single subharmonic, which is usually the fundamental space harmonic. The useful torque producing component is a higher order harmonic. The fundamental harmonic generates significant losses in the electric machine particularly in the rotor. For example, considering the $2 / 5 \mathrm{slot} / \mathrm{pole} /$ phase family, the fifth harmonic is the torque producing component while the first or the fundamental can be targeted (to be eliminated or reduced) by the stator shifting technique. Additionally, another loss producing harmonic, namely the seventh harmonic can also be targeted by stator shifting. These details are discussed in this section.

The effect of shift angle on the harmonic winding factors of a $2 / 5$ spp single-layer designs is seen in Fig. 5. Designs with shift angles belonging to each of the good grey regions are considered in this section and are analyzed.

The first of the grey regions extends from a shift angle of $340^{\circ}$ to $390^{\circ}$, where the winding factor of the fifth harmonic is higher than 0.933 ( $\mathrm{k}_{\mathrm{w} 5}$ is 0.966 in zero shift case), while the fundamental (first) winding factor lies around $0.2\left(\mathrm{k}_{\mathrm{w} 1}\right.$ is 0.258 in zero shift case) and the seventh harmonic varies from 0.5 to $0.067\left(\mathrm{k}_{\mathrm{w} 7}\right.$ is 0.966 in zero shift case). Hence, in this region, there is a significant drop in the seventh harmonic, while the fundamental is not affected in a big way.

A second region can be identified from a shift angle of $690^{\circ}$ to $750^{\circ}$. In this region, the fundamental is reduced to lower values (lower than 0.1), while the seventh harmonic varies from 0.5 to 0.933 .

In the first of the regions, it is clear that the seventh is effectively reduced, while in the second region, the fundamental harmonic is minimized. The variation of different winding factors is shown in Table II.

TABLE II Identification of Two Favorable Regions

\begin{tabular}{|l|l|l|l|}
\hline Harmonic & Baseline & Region-1 & Region-2 \\
\hline $1^{\text {st }}$ & 0.258 & $0.214 \rightarrow 0.201$ & $0.092 \rightarrow \mathbf{0 . 0 6 6}$ \\
\hline $5^{\text {th }}$ & 0.966 & $0.951 \rightarrow 0.933$ & $0.933 \rightarrow 0.933$ \\
\hline $7^{\text {th }}$ & 0.966 & $0.511 \rightarrow \mathbf{0 . 0 5 0}$ & $0.526 \rightarrow 0.933$ \\
\hline
\end{tabular}


One of the state-of-art approaches [12] looks at one of the angles in region-1, i.e., approximately $380^{\circ}$. However, in the current paper, it is shown that there exist other optimal shift angles for the $2 / 5$ slot/pole configuration and the final angle depends on the number of winding layers and slot/pole combination.

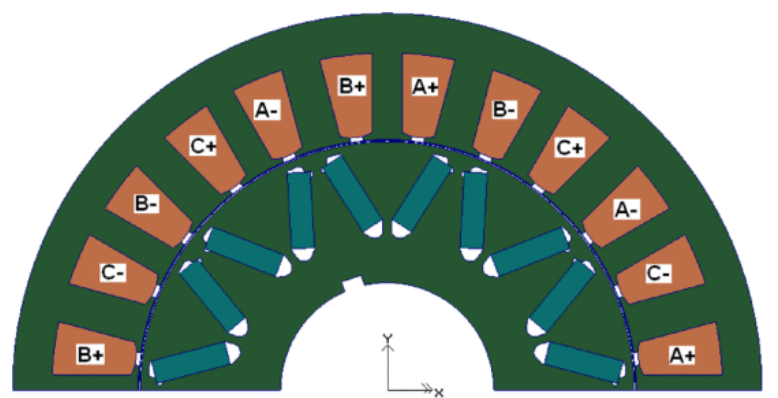

Fig. 8. Final 10-pole, 24-slot machine with shift angle of $380^{\circ}$.

The cross sections of two of the designs with $380^{\circ}$ and $700^{\circ}$ shift angles, along with the winding configurations, are shown Figs. 8 and 9, respectively. Note that the rotor is the same between the various designs as well as the material properties. Additional designs between $340^{\circ}$ and $390^{\circ}$ and $690^{\circ}$ and $710^{\circ}$ are considered, with the discussion more focused on shift angles of $380^{\circ}$ and $700^{\circ}$. As described in the previous section, all designs are sized to provide the peak power of $55 \mathrm{~kW}$ within the allowable current limit of $400 \mathrm{Arms}$ and a voltage limit of $325 \mathrm{Vdc}$.

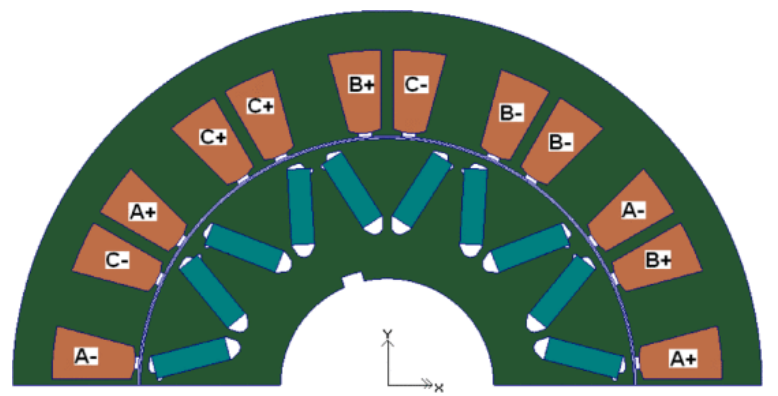

Fig. 9. Final 10-pole, 24-slot machine with shift angle of $700^{\circ}$.

The required stack length needed for each of the designs is shown in Fig. 10. While the baseline single-layer design is $96.5 \mathrm{~mm}$ long, shift angles in region- 1 and 2 can drop the machines to $91.1 \mathrm{~mm}$ and $85.2 \mathrm{~mm}$. In this configuration, it is seen that designs in region-2 are significantly shorter than region-1, due to the reduction of the fundamental harmonic, while keeping the seventh harmonic with a reasonable value. There is almost $11 \%$ improvement in power density of the machine compared to the baseline case of zero shift. This is mainly due to the lower saturation effects and higher saliency/reluctance torque. 


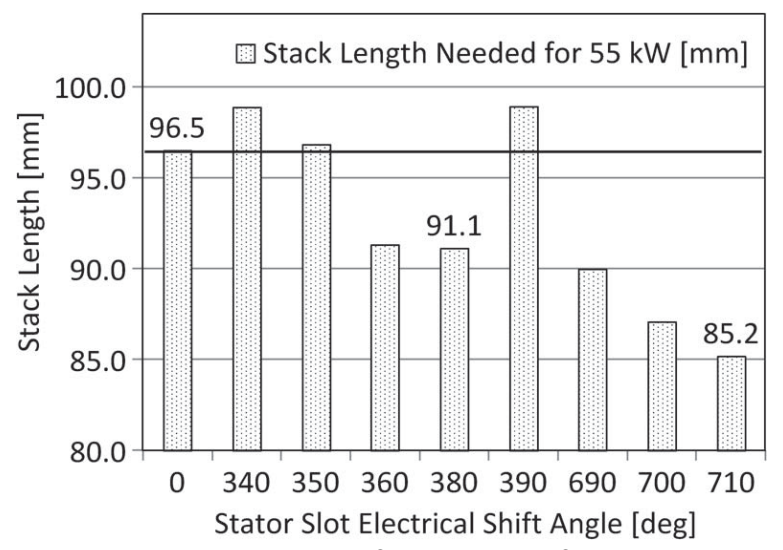

Fig. 10. Stack lengths of various shifted 10 -pole, 24 slot $2 / 5$ single-layer designs.

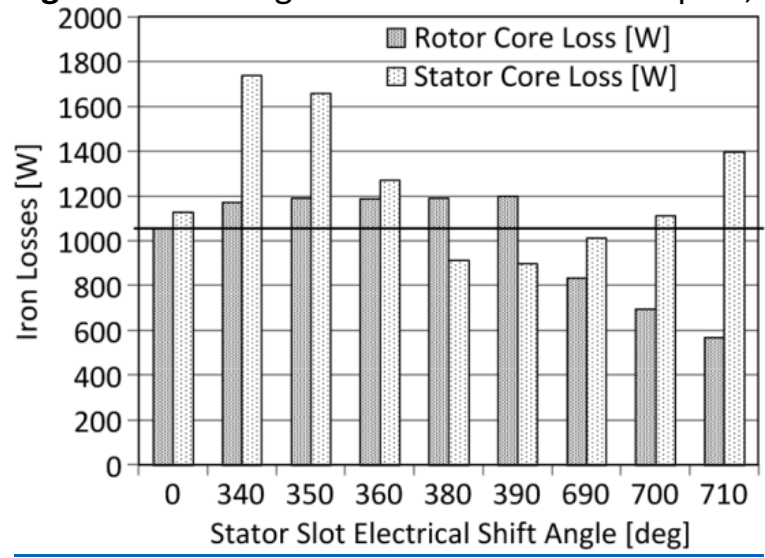

Fig. 11. Core loss breakdown for various shifted 10-pole, 24 slot $2 / 5$ single-layer designs.

Reduction of the harmonics by shifting is reflected in the reduction of the rotor harmonic losses as shown in Fig. 11. Both of the designs in region- 1 and -2 can reduce rotor losses, while increasing the stator losses due to increase of flux densities in the stator (presence of nonworking teeth in the stator). In one of the cases in region2 , i.e., shift angle of $710^{\circ}$, while the rotor losses are reduced by almost $50 \%$, the stator losses increase only by $23 \%$. Such a variation can result in a machine with better efficiency compared to the baseline (zero shift) case.

The efficiencies of the various designs plotted in Fig. 12 indicate that the proper shifting for the reduction of the harmonics leads to improvement of the efficiency at the top speed of $14000 \mathrm{r} / \mathrm{min}$ by almost $0.75 \%(225 \mathrm{~W})$. Clearly, the shift angles in region-2 have shown that it is possible to significantly improve the power density of the machine while being able to improve the efficiency of the machine at the top operating speed of 14000 $\mathrm{r} / \mathrm{min}$, which is usually a difficult goal to achieve.

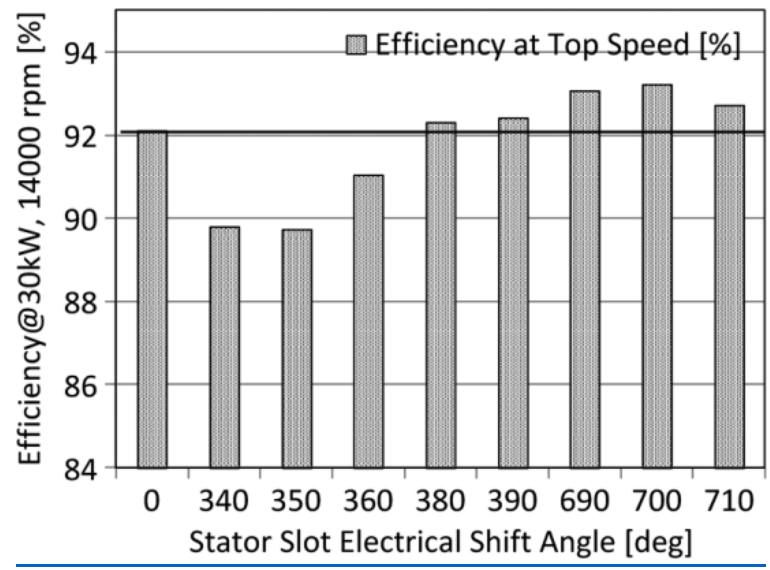


Fig. 12. Efficiency of various shifted 10 -pole, 24 slot $2 / 5$ single-layer designs.

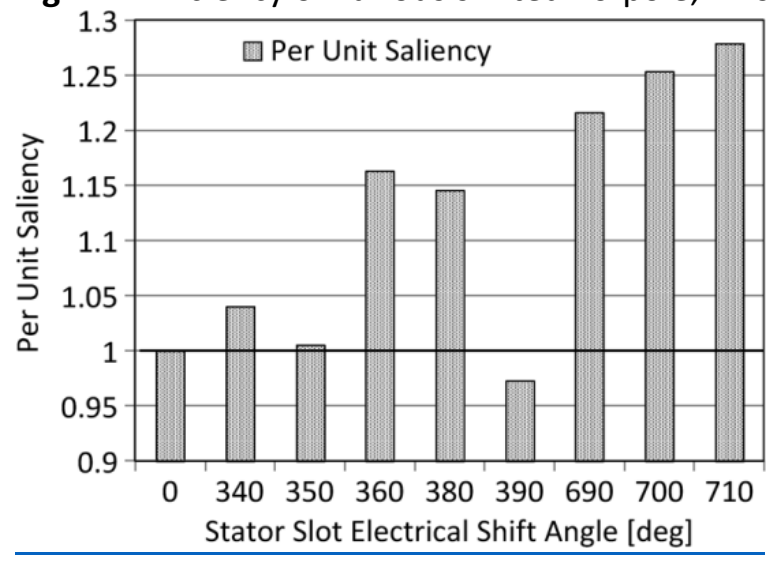

Fig. 13. Per-unitized saliency at peak power conditions.

Some of the other metrics that show up in improvement of the power density are the per unit saliency at the peak power conditions in Fig. 13. The saliency in this case is per unitized to the saliency estimation for the baseline case, with the saliency itself defined based on the differential inductances (rather than frozen permeance methods). The saliency ratio directly depends on the saturation level of the working harmonic as well as the presence of other harmonic components. For example, in the $2 / 5$ single-layer winding machine, the saliency is mainly determined by the MMF of the working harmonic, i.e., the fifth harmonic while the other harmonics namely the fundamental and the seventh harmonic affects the saturation level in the machine. This disturbs (or saturates) the paths available for the working harmonic and hence affects the saliency. The graphs shown in Figs. 5 and 13 show the winding factor and the saliency ratio achieved in the 2/5th single-layer designs as a function of shift angle in electrical degrees. Notice that the saliency ratio increases with the winding factor of the torque-producing fifth harmonic. It also increases with the reduction of fundamental harmonic winding factor. In other words, the reduction of the fundamental harmonic reduces the saturation level and hence the machine saliency ratio increases.

One of the effects of stator shifting is the reduction of the harmonic leakage inductance in each of the phases. Making the windings more distributed has an effect on reducing the inductance, which has a direct effect of increasing the characteristic current, which further has an effect on increasing the maximum achievable power at the top speed. The maximum power achievable with a current limit of $200 \mathrm{Arms}$, and a nominal voltage limit of 325 VDC is shown in Fig. 14, while the characteristic current is shown in Fig. 15. The maximum power, based on the electromagnetic limitations, improves considerably from the baseline case. This will also potentially increase the constant power speed ratio (CPSR) if mechanically permissible.

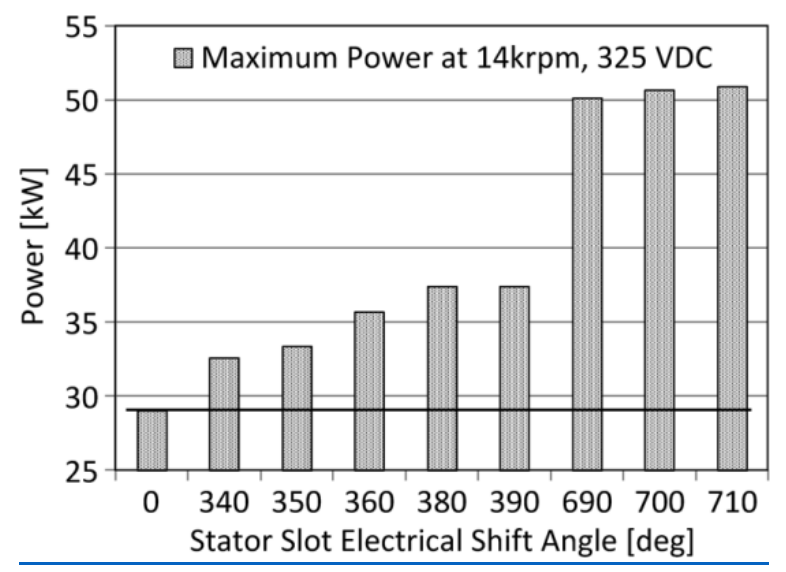


Fig. 14. Maximum power achievable at top speed with 200 Arms, 325 VDC limit.

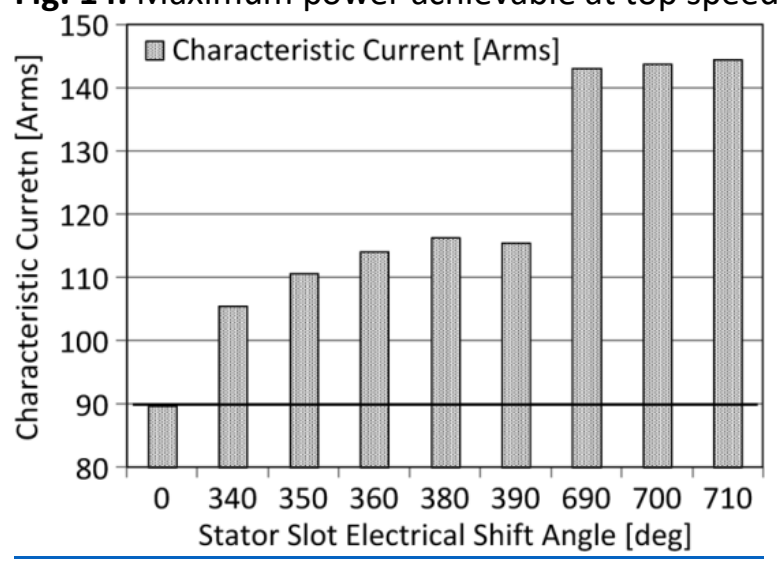

Fig. 15. Characteristic current for various shifted 10 -pole, 24 slot $2 / 5$ single-layer designs.

The effect of shifting on the torque ripple for the single-layer designs belonging to the $2 / 5$ spp family is seen in Fig. 16. The results indicate that the torque ripple is more sensitive to the higher order harmonics and hence the lowest ripple occurs in cases with the lower higher order harmonics (particularly the seventh).

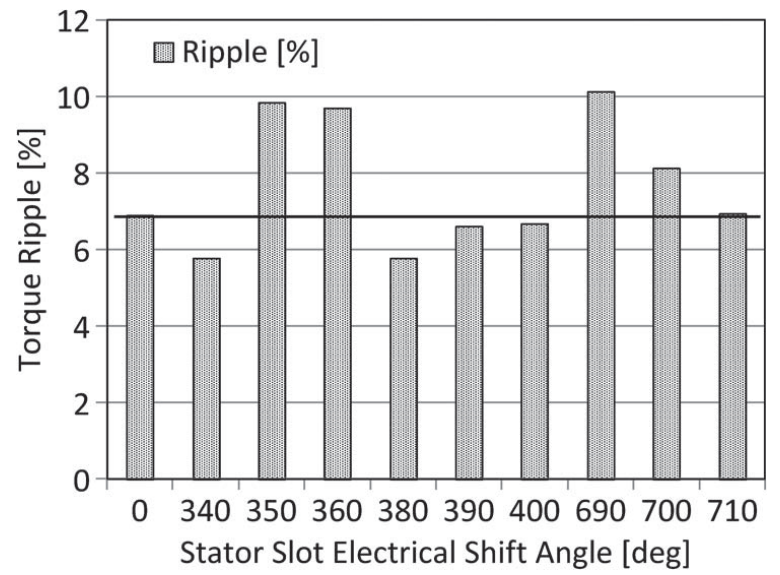

Fig. 16. Torque ripple for various shifted 10 -pole, 24 slot $2 / 5$ single-layer designs.

Based on the analysis of the various shift angles, the final design with the shift angle of $710^{\circ}$ seems to be the "optimal" design.

\section{SECTION V. Effects of Stator Shifting on Double-Layer Windings}

As previously mentioned and well established in literature, FSCW, designs with double-layer windings have a lower fundamental harmonic component than the single-layer windings. In these windings, the stator shifting technique can target the next (major) loss-producing higher order harmonic component instead of the fundamental harmonic component.

For the same family considered above, i.e., the $2 / 5$ slot/pole/phase family, the double-layer winding configuration has been shown in Fig. 4. The stator shifting technique can be used to target the seventh harmonic rather than the fundamental. This section includes the results of this procedure in case of the double-layer windings.

The effect of the shift angle on the winding factors of the double-layer windings is similar to that of the singlelayer winding and is shown in Fig. 19. Similar regions as the single-layer winding are identified for the double- 
layer windings. One of the big differences compared to the single-layer winding is that the fundamental is very low in the double-layer winding. This benefits designs where the fundamental harmonic is a bigger problem, i.e., region-1.

The cross sections of the designs with shift angles of $380^{\circ}$ and $700^{\circ}$ are shown in Figs. 17 and 18, respectively. Designs belonging to both regions are analyzed with focus on the above two designs.

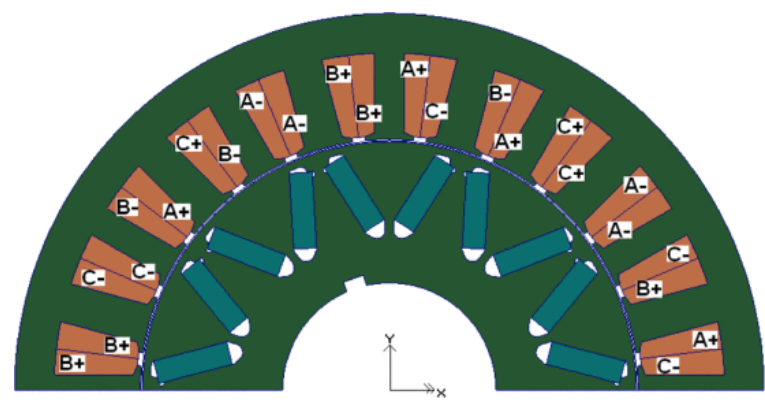

Fig. 17. Final 10-pole, 24-slot machine with double-layer windings and shift angle of $380^{\circ}$.

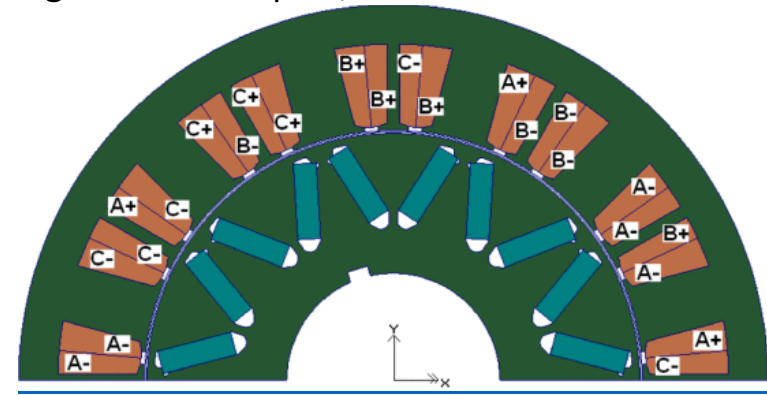

Fig. 18. Final 10-pole, 24-slot machine with double-layer windings and shift angle of $700^{\circ}$.

The stack lengths of the various double-layer designs needed to produce the $55 \mathrm{~kW}$ peak power are shown in Fig. 20. One of the significant change from the single-layer winding designs is that baseline design, i.e., zero shift case is shorter than the single-layer baseline design by about $10 \%$. Such a good start for the double-layer designs is possible due to the lower fundamental harmonic. Furthermore, the improvement with shift angles is clearly beneficial in region-1. The design with shift angle of $380^{\circ}$ has an improvement of another $9 \%$ in power density compared to the baseline design, whereas the design in region- 2 only improves by $5 \%$. The difference in these improvements is due to the reason that the seventh harmonic is negligible in the design with shift angle of $380^{\circ}$ design compared to the design with shift angle of $700^{\circ}$.

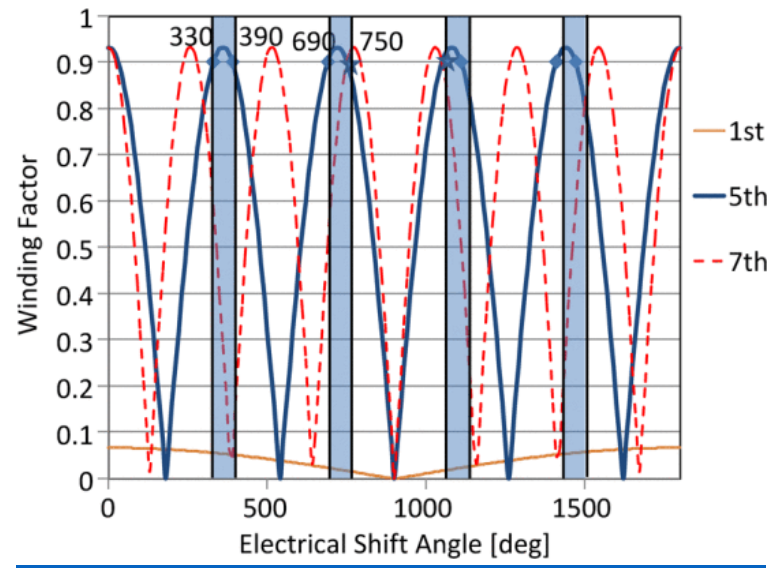

Fig. 19. Effect of the shift angle on winding factors of first, fifth, and seventh harmonics in $2 / 5$ spp family with double-layer windings. 


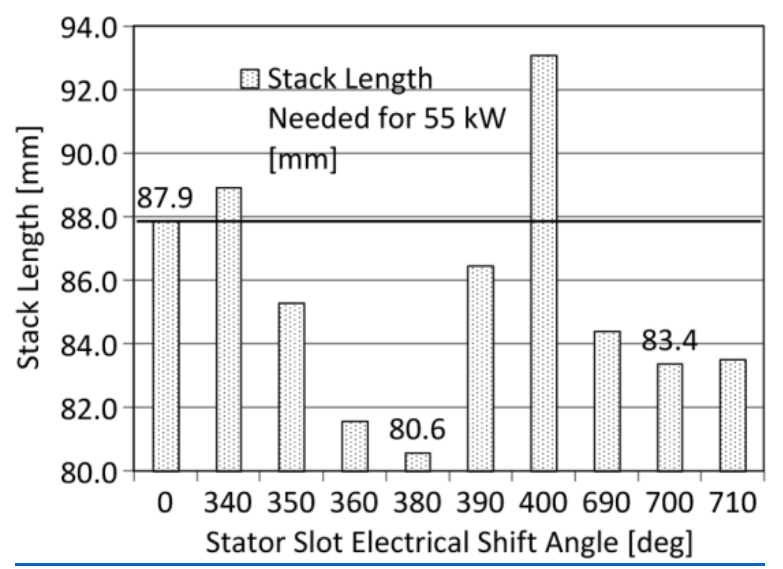

Fig. 20. Stack lengths of various shifted 10 -pole, 24 slot $2 / 5$ double-layer designs.

Based on the above reasoning, clearly the efficiency in the case with $380^{\circ}$ is much better than $700^{\circ}$. This is evident from the efficiency chart shown in Fig. 21. The efficiencies of shifted designs of $380^{\circ}$ and $700^{\circ}$ have better efficiency than the baseline case, with the $380^{\circ}$ improving the efficiency by more than $1 \%$ at the top speed.

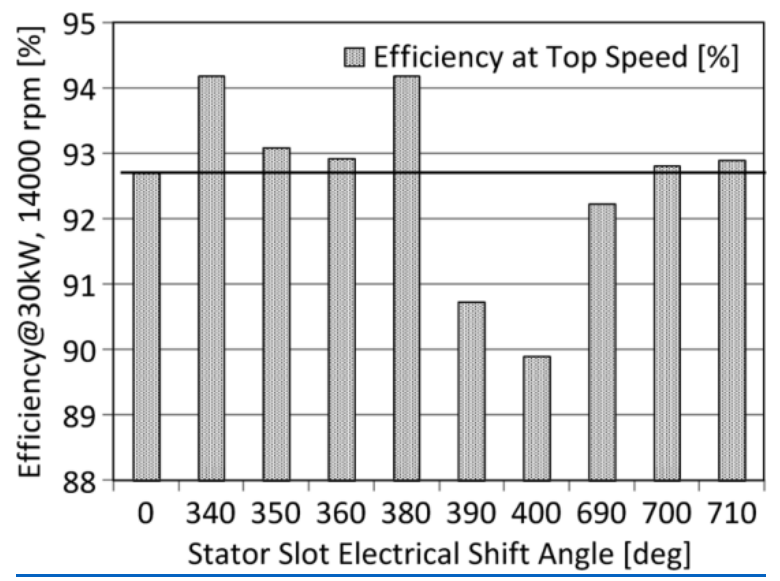

Fig. 21. Efficiency of various shifted 10-pole, 24 slot 2/5 double-layer designs.

The improvement in per-unitized saliency along with maximum available electromagnetic power and characteristic current is consistent with the trends seen in the single-layer designs discussed in the previous section. The results are shown in Figs. 22 and 23, respectively. Interestingly, in the double-layer designs, the designs in region- 1 are better than those of region-2, due to the reasons previously mentioned. 


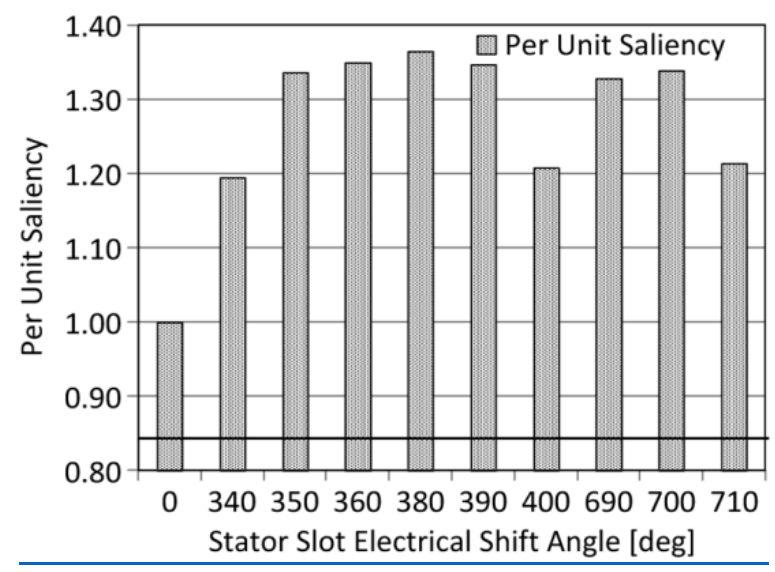

Fig. 22. Per-unitized saliency at peak power conditions in double-layer designs of $2 / 5$ slot/pole configuration.

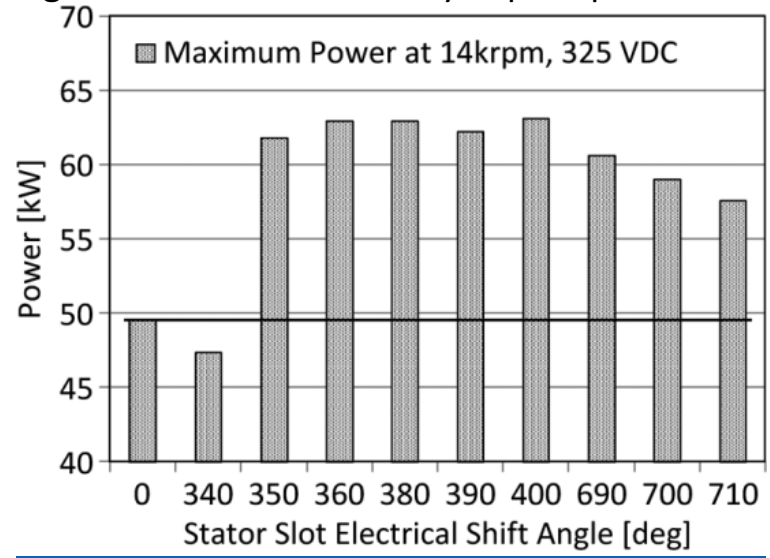

Fig. 23. Maximum power achievable at top speed with 200 Arms, 325 VDC limit with 2/5 double-layer designs.

Reduction of the seventh harmonic has a considerable reduction effect on torque ripple in the double-layer designs as shown in Fig. 24. Additionally, since the fundamental in the double-layer designs is lower than the single-layer designs, the overall torque ripple is lower than those of the single-layer designs.

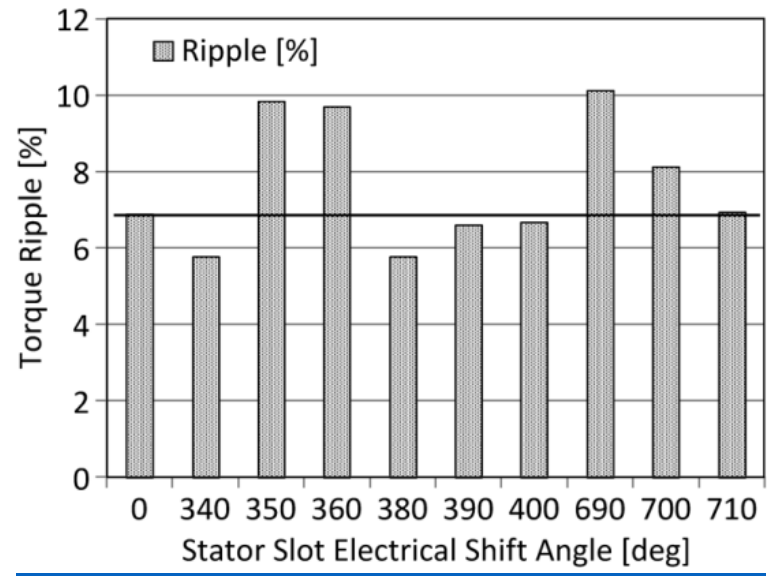

Fig. 24. Torque ripple for various shifted 10 -pole, 24 slot $2 / 5$ double-layer designs.

\section{SECTION VI. Saturation, End-End Length, and Radial Forces}

This section will investigate and quantify the impact of the stator shifting concept on the machine saturation level, end-end length as well as radial forces. 
The introduction of the stator shift does have an impact on the saturation level in the stator as well as radial forces. The peak tooth flux density in the baseline single-layer winding design with no stator shift as well as the two designs with the two most favorable shift angles is summarized in Table III.

TABLE III Peak Tooth Flux Density in Single-Layer Designs

\begin{tabular}{|l|l|l|l|}
\hline Shift Angles & 0 & 380 & 710 \\
\hline Teeth Flux & $1.85 \mathrm{~T}$ in each teeth & $\begin{array}{l}1.80 \mathrm{~T} \text { in wide teeth } \\
1.9 \mathrm{~T} \text { in narrow teeth }\end{array}$ & $\begin{array}{l}1.84 \mathrm{~T} \text { in wide teeth } \\
1.9 \mathrm{~T} \text { in narrow teeth }\end{array}$ \\
\hline
\end{tabular}

In order not to oversize the design as well as maximize the machine power density, it is understood that the flux density in each tooth is pushed to the limit and hence the narrower tooth tends to be more saturated than the wider teeth. The flux density in all the teeth reaches the vicinity of saturation limit of $1.85 \mathrm{~T}$.

The flux density cross sections in different cases in double layer is shown in Figs. 25-27 at the peak power condition, while Figs. 28-30 show the flux densities at the power of $30 \mathrm{~kW}, 14000 \mathrm{r} / \mathrm{min}$ operating point.

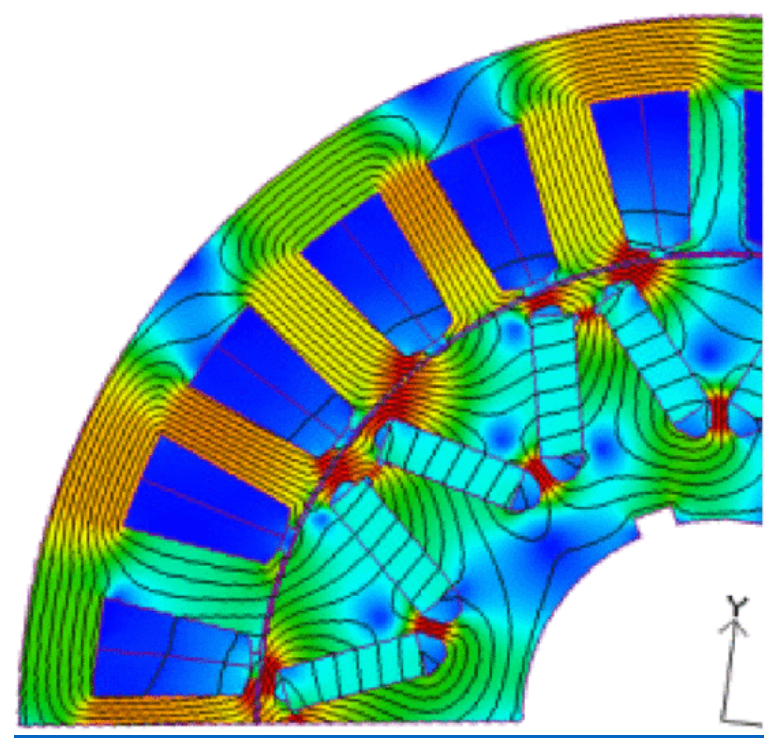

Fig. 25. Flux density at $55 \mathrm{~kW}$ and $2800 \mathrm{r} / \mathrm{min}$ at $380^{\circ}$.

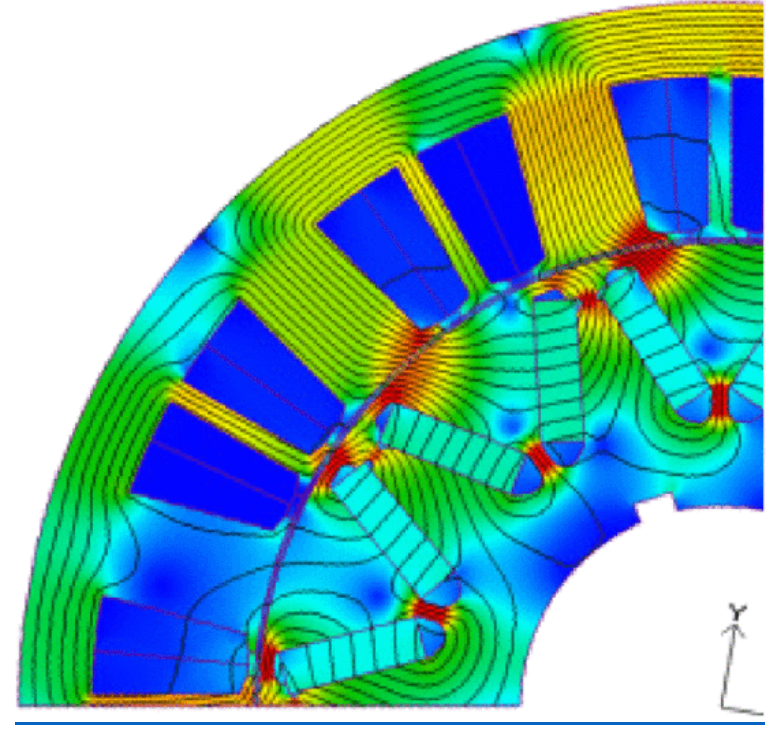

Fig. 26. Flux density at $55 \mathrm{~kW}$ and $2800 \mathrm{r} / \mathrm{min}$ at $700^{\circ}$. 


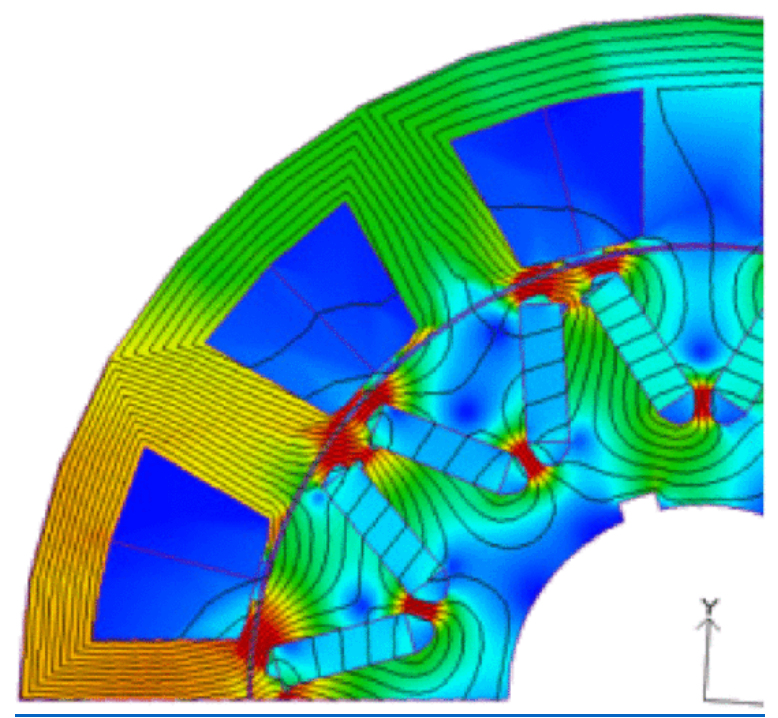

Fig. 27. Flux density at $55 \mathrm{~kW}$ and $2800 \mathrm{r} / \mathrm{min}$ at $0^{\circ}$.

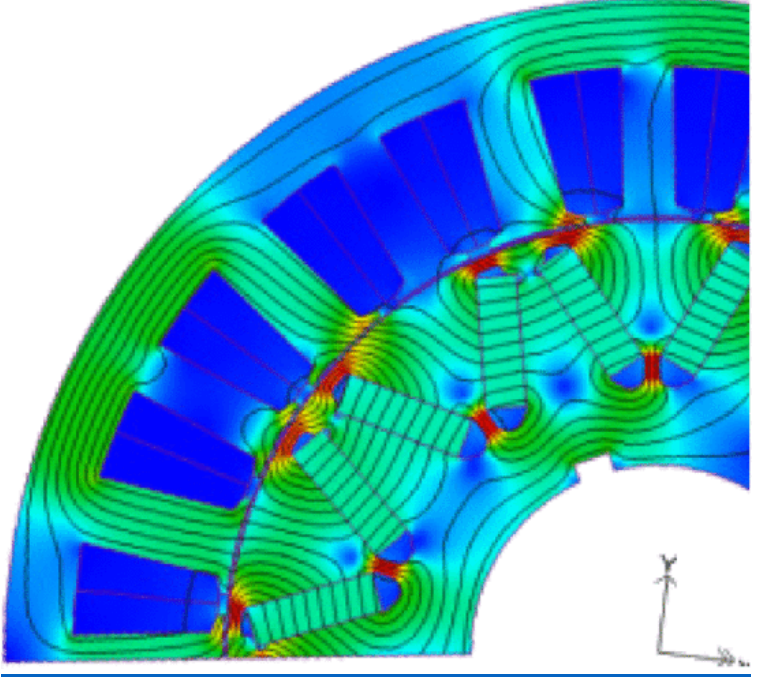

Fig. 28. Flux density at $30 \mathrm{~kW}$ and $14000 \mathrm{r} / \mathrm{min}$ at $380^{\circ}$.

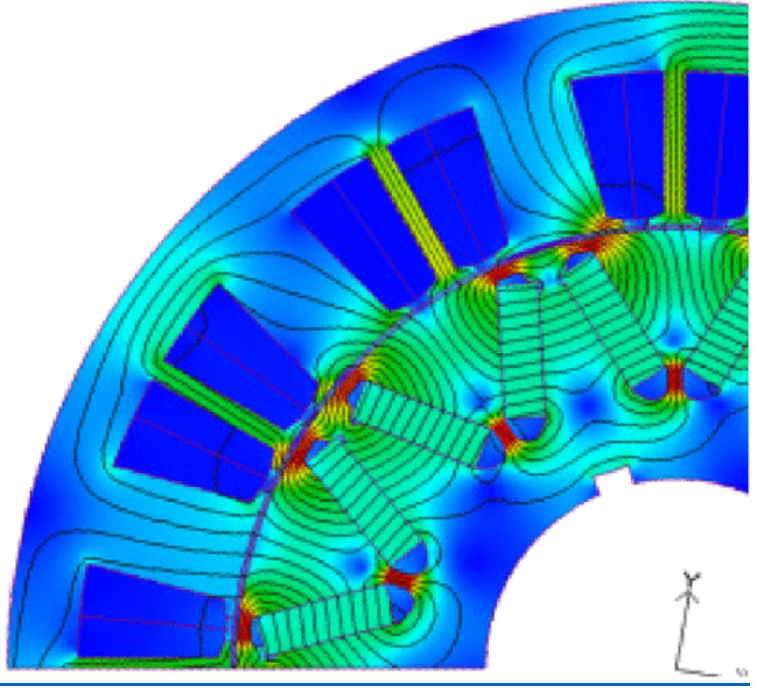

Fig. 29. Flux density at $30 \mathrm{~kW}$ and $14000 \mathrm{r} / \mathrm{min}$ at $700^{\circ}$. 


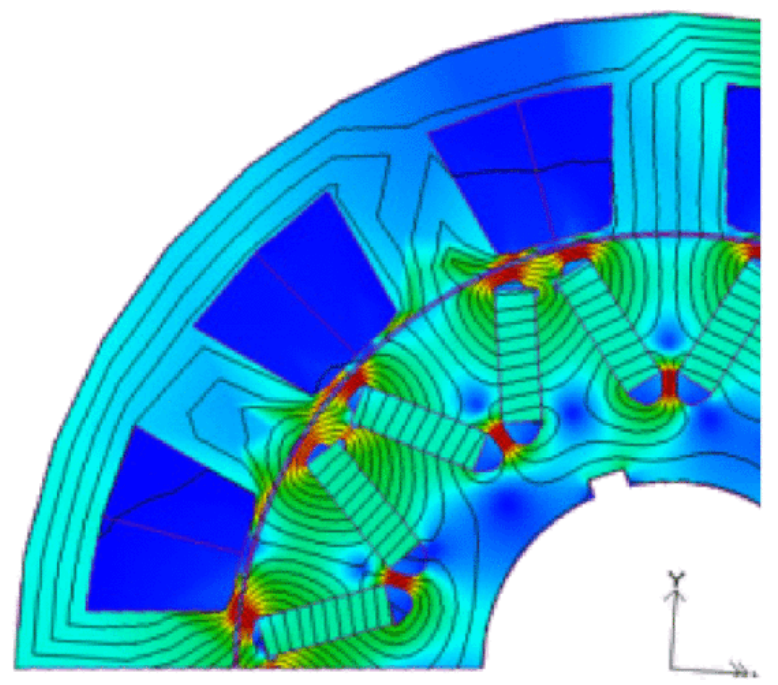

Fig. 30. Flux density at $30 \mathrm{~kW}$ and $14000 \mathrm{r} / \mathrm{min}$ at $0^{\circ}$.

TABLE IV Estimation of End-End Length and Resistance

\begin{tabular}{|l|l|l|}
\hline & Zero Shift & $380^{\circ} / 710^{\circ}$ Shift \\
\hline Slots & 12 & 24 \\
\hline Slot Pitch & 1 & 2 \\
\hline Stack & $96.5 \mathrm{~mm}$ & $85.2 \mathrm{~mm}$ \\
\hline Axial Extension of Coil at Slot & $0.5 \mathrm{~mm}$ & $2.5 \mathrm{~mm}$ \\
\hline Axial End-Stack Length & $28.0 \mathrm{~mm}$ & $51.0 \mathrm{~mm}$ \\
\hline End-end Length of Machine & $248.9 \mathrm{~mm}$ & $256.4 \mathrm{~mm}$ \\
\hline MLT & $357.4 \mathrm{~mm}$ & $302.3 \mathrm{~mm}$ \\
\hline Resistance & $13.1 \mathrm{mOhm}$ & $12.1 \mathrm{mOhm}$ \\
\hline
\end{tabular}

The volumetric power density, defined as $\mathrm{kW} / \mathrm{l}$, has to be evaluated based on the total end-end length of the machine up to the total radius. The end-end length of the machine is the sum of the stack length as well as the length for the end windings (see Table IV). If we compare the baseline 12 slot/10pole design with the 24 slot/10 pole designs with optimum shift angles, the reduction of the stack length (due to increase in machine saliency and hence reluctance torque) is countered by the increase in the length of the end windings. The axial length of the end windings is increased by the "axial extension" needed for the end windings which is a function of the coil pitch as well as the thickness of the coil itself.

Hence, the end-end length of the machine increases from $248.9 \mathrm{~mm}$ to $256.4 \mathrm{~mm}$, which is about $3 \%$ of the total machine length.

The copper losses have been calculated based on the MLT (mean turn length) of each phase. In this calculation, the mean turn length is equal to the sum of twice the stack length and twice the total end-winding length on each side the machine. The end-windings of the proposed machine fall into a special class of designs where the slot pitch is always two. Hence, the end-windings connect every slot to every other slot (the slot which is numbered third from the first slot). This means that 1 ) the end-windings are longer, 2) care is taken to have proper extension to include the fact that the windings are overlapping (as per standard definitions).

As seen from the table above, the equivalent resistance decreases by about $8 \%$ in the overall value. 
Under the open-circuit fields, the fundamental component of force density is reduced by shifts which mean that the cogging torque component reduces due to presence of higher number of slots. However, under the conditions of full load, looking at the first two harmonic components, the fundamental component of radial force density increases while the third harmonic components decreases with the presence of shift (see Figs. 31 and 32). This change is due to the introduction of imbalance of the EM forces over the entire rotor structure, wherein the benefit of the higher power density is achieved at the expense of the higher radial forces.

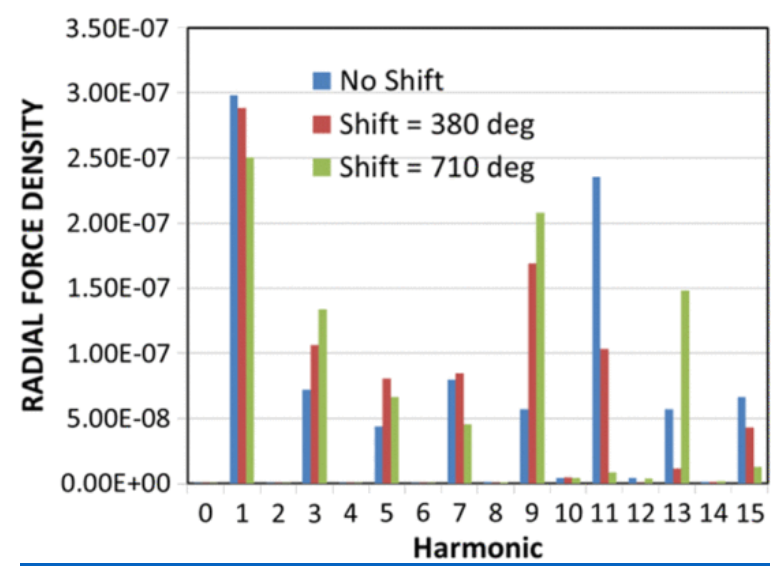

Fig. 31. Harmonic components of radial force density under open circuit condition.

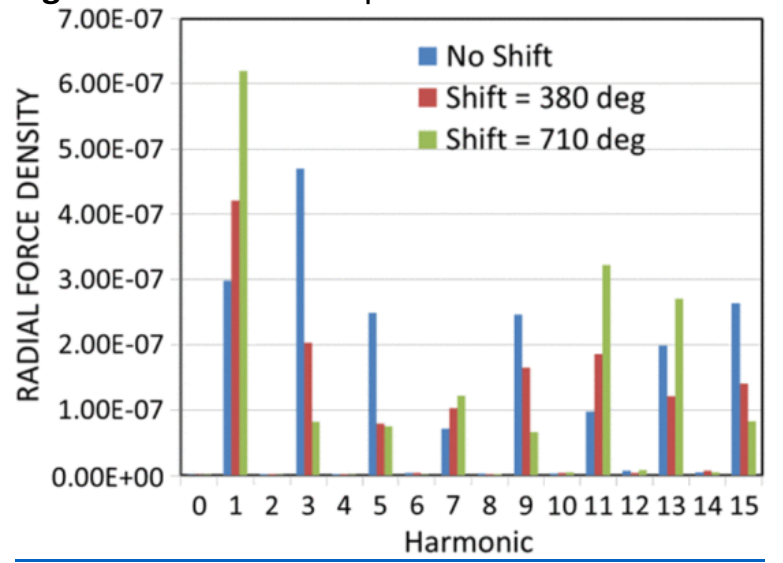

Fig. 32. Harmonic components of radial force density under load.

\section{SECTION VII. Conclusion}

This paper investigated a generalized method of cancellation of harmonics in fractional slot concentrated windings. The concept of stator shifting is introduced in IPM motor and its effect on the machine performance in terms of the power density, efficiency, torque ripple, and flux weakening performance was evaluated.

The concept of stator shifting is introduced in terms of the electrical angle of the working harmonic in the FSCW machines also denoted as the shift angle of the stator. In these machines, it is noted that the optimal range of the shift angle depends on the harmonic content of the stator, namely depending on the sub- and superharmonics in the stator.

In the single-layer winding designs, the optimal shift angles are aimed at the reduction of the fundamental space harmonic of the stator. The shifted stator is seen to improve saliency in the considered IPM machine and thereby improve the torque density by $12 \%$, while keeping the same rotor. Introduction of the shift angle is also seen to shift the losses from the rotor to the stator, while the overall efficiency numbers being similar to the 
original machine. The improved saliency is also seen to improve the characteristic current and hence the power at the top speeds.

Double-layer winding designs are seen to have a different optimal range of the shift angles, where the shift angle is aimed at the immediate superharmonic of the working harmonic. These double-layer shifted stator designs are considered as a further step from the single layers in terms of harmonic reduction, by the reduction of both the fundamental and the superspace harmonic. For this reason, the double-layer shift designs fare better than the single-layer shifted designs both in terms of the torque density as well as efficiency.

The complexity of winding of the shifted stator is seen to be lesser than that of a distributed winding but higher than that of a tooth winding. Since the coil pitch in the shifted stators is always two, which can greatly reduce the end-winding length compared to a distributed winding, while being able to achieve better performance than the tooth windings. In other words, this concept gets the best of both worlds. Finally, the concept of stator shifting is seen to be more effective in designs with a single subharmonic. In slot/pole combinations with multiple subharmonics, the improvement is curtailed by the effect of these harmonics.

The key novelty in the paper is that it explored the effect of shift angle in more general way by scanning a wide range of angles. The paper also highlighted the fact that once high-speed operation under flux-weakening operation is taken into consideration, this can affect the choice of the shift angle in terms of maximizing efficiency at high speeds.

Even though it can be seen that an improvement in power density can be seen in IPM machines due to the improvement in saliency, in surface PM machines, it is expected that the shifting would reduce the harmonics and hence only reduce the rotor losses but will simultaneously reduce the power.

The summary of the conclusions in the $2 / 5$ th slot/pole/phase combination has been quantified in Table V. Some of the improvements achieved by the introduction of the stator shift in region-1 have been shown in the total stack length needed to produce $55 \mathrm{~kW}$ along with the saliency at this operating point, efficiency at top speed of $14 \mathrm{krpm}$ along with the maximum power available at the top speed within the current and voltage specifications. The improvement represents $13 \%$ reduction in stack length (increase in power density), $0.8 \%$ improvement in efficiency at top speed, and $70 \%$ increase in maximum power at the top speed.

TABLE V Comparison of Original and Shifted Stator Design

\begin{tabular}{|l|l|l|}
\hline Parameter & Original & Shifted Stator \\
\hline Shift Angle & $0^{\circ}$ & $710^{\circ}$ \\
\hline Slot/Pole/Phase & $2 / 5$ & $4 / 5$ \\
\hline Working Harmonic & $5^{\text {th }}$ & $5^{\text {th }}$ \\
\hline Winding Factor & 0.966 & \\
\hline Stack Length for 55 kW [mm] & 96.5 & 85.2 \\
\hline Efficiency at 30 kW, 14000 rpm [\%] & 92.0 & 92.8 \\
\hline Per-Unit Saliency & 1.0 & 1.27 \\
\hline Maximum power at $14000 \mathrm{rpm}[\mathrm{kW}]$ & 29.5 & 50.2 \\
\hline Torque Ripple & 6.9 & 7.1 \\
\hline
\end{tabular}




\section{References}

1. A. M. El-Refaie, M. R. Shah, J. P. Alexander, S. Galioto, K.-K. Huh and W. D. Gerstler, "Rotor end losses in multiphase fractional-slot concentrated-winding permanent magnet synchronous machines", IEEE Trans. Ind. Appl., vol. 47, no. 5, pp. 2066-2074, Sep./Oct. 2011.

2. J. K. Tangudu, T. M. Jahns and A. El-Refaie, "Core loss prediction using magnetic circuit model for fractionalslot concentrated winding interior permanent magnet machines", Proc. IEEE ECCE, pp. 1004-1011, 2010.

3. D. Ishak, Z. Q. Zhu and D. Howe, "Comparison of PM brushless motors having either all teeth or alternate teeth wound", IEEE Trans. Energy Convers., vol. 21, no. 1, pp. 95-103, Mar. 2006.

4. D. Ishak, Z. Q. Zhu and D. Howe, "Comparative study of permanent magnet brushless motors with allt teeth and alternative teeth windings", Conf. Rec. 2nd IEE Int. PEMD, vol. 2, pp. 834-839, 2004-Mar./Apr.

5. A. M. El-Refaie and T. M. Jahns, "Impact of winding layer number and magnet type on synchronous surface PM machines designed for wide constant-power speed range operation", IEEE Trans. Energy Convers., vol. 23, no. 1, pp. 1486-1493, Oct. 2006.

6. M. V. Cistelecan, F. J. T. E. Ferreira and M. Popescu, "Three phase tooth-concentrated multiple-layer fractional windings with low space harmonic content", Proc. IEEE ECCE, pp. 1399-1405, 2010.

7. Electric machine, Oct. 2009.

8. Elektrische maschine, Oct. 2008.

9. Dynamo-electric machine, Dec. 2000.

10. A. Di Gerlando, R. Perini and M. Ubaldini, "High pole PM synchronous motors with concentrated coil armature winding", Proc. Int. Conf. Elect. Mach., 2004.

11. Permanent magnet dynamo electric machine and permanent magnet synchronous generator for wind power generation, May 2005.

12. G. Dajaku and D. Gerling, "A novel 24-Slots/10-Poles winding topology for electric machines", Proc. IEEE IEMDC, pp. 65-70, 2011-May-15-18.

13. P. B. Reddy, A. El-Refaie and K.-K. Huh, "Effect of number of layers on fractional slot concentrated winding interior PM machines", Proc. ECCE, pp. 1921-1928, 2011.

14. Development of power electronics and electric motor technology for plug-in hybrid electric vehicles internal combustion engine hybrid electric vehicles and fuel cell vehicle traction drive applications, pp. 9-10, Jan. 2006.

15. P. B. Reddy, A. El-Refaie, K.-K. Huh, J. K. Tangudu and T. M. Jahns, "Comparison of interior and surface PM machines equipped with fractional-slot concentrated windings for hybrid traction applications", Proc. IEEE ECCE, pp. 2252-2259, 2011-Sep.-17-22.

16. P. B. Reddy, A. El-Refaie and K.-K. Huh, "Effect of stator shifting on harmonic cancellation and flux weakening performance of interior permanent magnet machines equipped with fractional-slot concentratedwindings for hybrid traction applications", Proc. Conf. ECCE, pp. 525-533, 2012-Sep.

17. J. Cros and P. Viarouge, "Synthesis of high performance PM motors with concentrated windings", IEEE Trans. Energy Convers., vol. 17, no. 2, pp. 248-253, Jun. 2002.

18. F. Magnussen and C. Sadarangani, "Winding factors and Joule losses of permanent magnet machines with concentrated windings", Proc. IEEE-IEMDC, vol. 1, pp. 333-339, 2003-Jun.

19. T. Fukami, Y. Matsuura, K. Shima, M. Momiyama and M. Kawamura, "A multipole synchronous machine with nonoverlapping concentrated armature and field windings on the stator", IEEE Trans. Ind. Electron., vol. 59, no. 6, pp. 2583-2591, Jun. 2012.

20. A. S. Abdel-Khalik and S. Ahmed, "Performance evaluation of a five-phase modular winding induction machine", IEEE Trans. Ind. Electron., vol. 59, no. 6, pp. 2654-2669, Jun. 2012. 